\title{
Schiavo on the Cutting Edge: Functional Brain Imaging and its Impact on Surrogate End-of-Life Decision-Making
}

\author{
Jon B. Eisenberg
}

Received: 1 November 2007 / Accepted: 3 December 2007 / Published online: 6 February 2008

(C) Springer Science + Business Media B.V. 2007

\begin{abstract}
The article addresses the potential impact of functional brain imaging (functional magnetic resonance imaging and positron-emission tomography) on surrogate end-of-life decision-making in light of varying state-law definitions of consciousness, some of which define awareness behaviorally and others functionally. The article concludes that, in light of admonitions by neuroscientists that functional brain imaging cannot yet replace behavioral evaluation to determine the existence of consciousness, state legislatures, courts and drafters of written advance healthcare directives should consider treating behavior, not function, as the touchstone for end-of-life decision-making.
\end{abstract}

Keywords Schiavo Advance directives $\cdot$ fMRI . PET End-of-life decision-making - Neural correlates of consciousness $\cdot$ Permanent vegetative state $\cdot$ Minimally conscious state $\cdot$ Artificial nutrition and hydration . Functional brain imaging

The author thanks Silvia A. Bunge, Ph.D., for her assistance in understanding functional brain imaging.

J. B. Eisenberg $(\bowtie)$

Eisenberg \& Hancock LLP, 1970 Broadway, Suite 1200, Oakland, CA 94612, USA

e-mail: jon@eandhlaw.com

\section{Introduction}

What if there had been a neurological test that would have shown whether Terri Schiavo was truly in a permanent vegetative state?

Maybe there was.

Statutes throughout the United States authorize surrogates to make end-of-life decisions - such as withholding or withdrawing artificial nutrition and hydration - on behalf of persons who have been diagnosed as being in a permanent vegetative state. Traditionally, this diagnosis is clinical, based on an assessment of behavior. Advances in brain-imaging technology, however, now enable neuroscientists to detect signs of cognitive brain function even where behavioral evidence of consciousness is absent.

This article addresses the potential impact of functional brain imaging on surrogate end-of-life decision-making in light of varying state-law definitions of consciousness, some of which define awareness behaviorally and others functionally. The article concludes that, in light of admonitions by neuroscientists that functional brain imaging cannot yet replace behavioral evaluation to determine the existence of consciousness, state legislatures, courts and drafters of written advance healthcare directives should consider treating behavior, not function, as the touchstone for surrogate end-of-life decisionmaking. 


\section{Bioethics and the Law of Surrogate End-of-Life Decision-Making}

Mainstream bioethicists treat personal autonomy - the right of control over one's body and one's medical care - as a central value underlying the traditions of Western medical practice. ${ }^{1}$ Personal autonomy is also firmly rooted in American law. As early as 1891, in Union Pacific Railway v. Botsford, the United States Supreme Court enunciated "the right of every individual to possession and control of his own person, free from all restraint or interference of others, unless by clear and unquestionable authority of law." 2 This includes a right not to have medical care, including artificial nutrition and hydration. In the landmark 1990 case of Cruzan v. Director, Missouri Department of Public Health, the Supreme Court said the right of "bodily integrity" is constitutionally guaranteed by the Due Process Clause of the Fourteenth Amendment and includes the right to refuse medical treatment. ${ }^{3}$

All states now have legislation addressing personal autonomy and the right to refuse treatment. Many statutes expressly authorize written advance directives for medical care; some include optional form advance directives that will satisfy the requirements of state law. ${ }^{4}$

When a patient is not competent, a surrogate must make healthcare decisions on the patient's behalf. Bioethicists have formulated three models for surrogate exercise of autonomy rights, with the goal of deciding how the patient would choose if he or she were able:

- Advance directive-If there is an advance directive giving instructions for future medical care, the surrogate follows the patient's instructions.

- Substituted judgment-If there is no advance directive or there is one but its instructions do not seem to cover the situation presented, and the patient previously had otherwise made known his or her preferences and values (for example, through conversations with friends and family

\footnotetext{
${ }^{1}$ See Hastings Center, Guidelines on the Termination of LifeSustaining Treatment and the Care of the Dying 6-8 (1987)

${ }^{2} 141$ U.S. 250, 251 (1891).

3497 U.S. 261, 278-279 (1990)

${ }^{4}$ See generally Alan Meisel \& Kathy L. Cerminara, The Right To Die $\S \S 8.01-10$ (3d ed. 2007)
}

members), the surrogate makes a decision based on the patient's subjective wishes, attempting to decide as the patient would have decided when competent.

- Best interests - If nothing is known about the patient's preferences and values, the surrogate makes a decision based on an objective assessment of the patient's best interests, attempting to decide as most people would choose under the circumstances. $^{5}$

State laws generally track these three bioethical models. Legislation in Florida - the venue of the Schiavo case - is exemplary: If a patient has an advance directive giving instructions for medical care, the surrogate must follow the advance directive. Absent an advance directive, the surrogate must make the health care decision that the surrogate "reasonably believes the patient would have made under the circumstances." 6 If there is no indication what the patient would have chosen, the surrogate "may consider the patient's best interest in deciding that proposed treatments are to be withheld or that treatments currently in effect are to be withdrawn."7

The extent of a surrogate's decision-making authority to withhold or withdraw artificial nutrition and hydration may depend, however, on the condition that has caused the patient's incompetence. Some states statutorily restrict such authority to patients whose incompetence is caused by coma or permanent vegetative state. ${ }^{8}$ And even in states where there is no such statutory restriction, the patient's advance directive might effectively impose the same restriction by specifically addressing only coma and permanent vegetative state, as do some form advance directives.

That is why Terri Schiavo's parents renounced her diagnosis of vegetative state. Florida's statutory authorization for removing feeding tubes mentions only "terminal condition," "end-stage condition," and "persistent vegetative state." 9 The statute does not mention another disorder of consciousness-the

\footnotetext{
${ }^{5}$ Hastings Center, supra note 1, at 27-28.

${ }^{6}$ Fla. Stat. $\S 765.401(2)$ (2007).

${ }^{7}$ Id.

${ }^{8}$ See, e.g., Ohio Rev. Code Ann. § 1337.13(B)(1) (West 2007).

${ }^{9}$ Fla. Stat. § 765.302(1) (2007). It is an open question, however, whether Florida's state constitution guarantees rights in end-of-life decision-making that are broader than those statutorily prescribed.
} 
"minimally conscious state." If Terri Schiavo had been diagnosed as being minimally conscious rather than vegetative, the outcome of the case might have been different.

Thus, in some cases, a diagnosis of minimally conscious instead of permanently vegetative can mean the difference between sustaining life rather than ending it. The distinction between the two - and an accurate diagnosis - becomes pivotal.

\section{The Permanent Vegetative State and the Minimally Conscious State}

The diagnosis of "permanent vegetative state" was formalized in 1994 by the Multi-Society Task Force on PVS, which described the vegetative state as "a clinical condition of complete unawareness of the self and environment." ${ }^{10}$ Unlike comatose patients, who have no spontaneous eye-opening and cannot be awakened, patients in a vegetative state have sleepwake cycles and will open their eyes when awake. ${ }^{11}$ They are, nevertheless, unconscious. Patients in a vegetative state "show no evidence of sustained, reproducible, purposeful, or voluntary behavioral responses to visual, auditory, tactile, or noxious stimuli; show no evidence of language comprehension or expression; have bowel and bladder incontinence; and have variably preserved cranial-nerve and spinal reflexes."12 Recovery from a vegetative state is unlikely after 1 year if traumatic in origin and 6 months if non-traumatic in origin. ${ }^{13}$ The condition is accurately called "persistent" at the outset and then "permanent" after passage of the time when recovery becomes unlikely. ${ }^{14}$ Nevertheless, in many statutes, judicial decisions and other sources, the phrase "persistent vegetative state" is commonly used to describe what is actually a permanent vegetative state.

The diagnosis of "minimally conscious state" was formalized in 2002 by the Aspen Neurobehavioral

\footnotetext{
${ }^{10}$ See Multi-Society Task Force on PVS, Medical Aspects of the Persistent Vegetative State, 330 New Eng. J. Med. 1499, 1499 (1994).

${ }^{11} \mathrm{Id}$.

${ }^{12} \mathrm{Id}$.

${ }^{13} I d$.

${ }^{14}$ Id.
}

Conference Workgroup, which described minimal consciousness as "a condition of severely altered consciousness in which minimal but definite behavioral evidence of self or environmental awareness is demonstrated." 15 Patients in a minimally conscious state demonstrate one or more of four types of behaviors on a reproducible or sustained basis: following simple commands; gestural or verbal yes/ no responses; intelligible verbalization; and purposeful (as opposed to reflexive) behavior. Purposeful behavior can include, for example, appropriate smiling or crying in response to emotional stimuli; vocalizing or gesturing in response to the linguistic content of questions; reaching for objects that demonstrates a clear relationship between object location and direction of reach; touching or holding objects in a manner that accommodates their size and shapes; and pursuit eye movements or sustained vision fixation in response to visual stimuli. ${ }^{16}$ Like vegetative patients, minimally conscious patients have severe immobility, are unable to perform activities of daily living, are unable to communicate meaningfully, have bladder and bowel incontinence, and require artificial nutrition and hydration. ${ }^{17}$ Meaningful recovery is unlikely after 1 year. ${ }^{18}$

The key difference between permanently vegetative and minimally conscious states is in awareness. The vegetative patient is completely unaware. The minimally conscious patient has some degree of awareness.

The minimally conscious state is sometimes misdiagnosed as permanent vegetative state. ${ }^{19}$ The diagnosis of both disorders can be difficult, for it is wholly clinical, requiring repeated examinations in a search for behavioral signs of awareness. ${ }^{20}$ There is no neurological test to distinguish between the two.

Or is there?

\footnotetext{
15 J.T. Giacino et al., The minimally conscious state, 50 Neurology 349, 350-51 (2002).

${ }^{16} \mathrm{Id}$. at 351 .

${ }^{17}$ Ronald E. Cranford, What is a minimally conscious state?, 176 West. J. Med. 129, 130 (March 2002).

18 J.T. Giancino et al., supra note 15 , at 352 .

${ }^{19} \mathrm{Id}$. at 350 .

${ }^{20}$ See Steven Laureys, Eyes Open, Brain Shut, Sci. Am. 34 (May 2007).
} 


\section{Functional Brain Imaging}

Brains scans produced by magnetic resonance imaging (MRI) and x-ray computed tomography (CT) provide structural images of brain anatomy, which can reveal brain damage but cannot detect signs of awareness. In contrast, brain scans produced by newer technology - functional magnetic resonance imaging (fMRI) and positron-emission tomography (PET) can indirectly indicate brain function.

Functional brain imaging targets neural brain activity, which leads to increased consumption of oxygen and glucose and a resulting increase in the flow of freshly-oxygenated blood to the most active regions of the brain. An fMRI scan detects such activity by measuring the surplus of oxygenated blood that is delivered to those regions. Oxygenated and deoxygenated hemoglobin in red blood cells have different magnetic properties, on which the fMRI relies to measure changes in the ratio of oxygenated and deoxygenated blood. ${ }^{21}$

A PET scan, in contrast, detects neural brain activity by measuring glucose consumption in different parts of the brain, enabling identification of the network of brain regions that is most active during performance of a given mental task. Radioactive isotopes attached to glucose molecules are injected into the patient, and the PET scan uses particle emissions from the isotopes to measure glucose consumption. (Relative to fMRI, PET imaging is more invasive and is not as widely available. $)^{22}$

Functional brain imaging indicates brain activation during one condition relative to another - such as visual stimuli versus no visual stimuli - by measuring neural activity in the brain regions that make sense of such stimuli. ${ }^{23}$ For example, activity in brain regions involved in speech comprehension might be detected

\footnotetext{
${ }^{21}$ See, e.g., S.A. Bunge \& I. Kahn, Cognition, Neuroimaging An Overview, in The Encyclopedia of Neuroscience (Adelman \& Smith, eds., 4th ed. in press); Joy Hirsch, Functional neuroimaging during altered states of consciousness: how and what do we measure?, in The Boundaries of Consciousness: Neurobiology and Neuropathology 25, 29 (Steven Laureys ed., 2005).

${ }^{22}$ See, e.g., S.A. Bunge \& I. Kahn, supra note 21; Susan A. Greenfield \& Toby F.T. Collins, A neuroscientific approach to consciousness, in The Boundaries of Consciousness, Neurobiology and Neuropathology 11, 12 (Steven Laureys ed., 2005).

${ }^{23}$ See, e.g., id.
}

upon reading aloud in the patient's native language versus an unknown language. Similarly, activity in brain regions involved in face recognition might be detected upon showing the patient pictures of family members versus strangers. Statistically significant neural activity as between the two conditions - called "neural correlates of consciousness" 24 - shows up as blobs of color on fMRI and PET images.

In a few instances, fMRI and PET scans have demonstrated neural correlates of consciousness in patients with no behavioral signs of awareness. For example, in a 2005 study of a 23-year-old woman who had sustained severe traumatic brain injury and showed signs of a vegetative state, fMRI imaging detected significant neural activity in motor-response regions of the woman's brain when she was asked to imagine playing tennis. ${ }^{25}$

This technology suggests an alternative to the traditional behavioral approach to ascertaining the presence or absence of awareness. If behaviorallydemonstrated signs of awareness are overt, fMRI and PET scans can be said to reveal signs of awareness that are covert, demonstrated functionally rather than behaviorally.

Can covert signs of awareness produced by fMRI or PET technology - a blob of color on a brain scan demonstrate that a patient is minimally conscious rather than permanently vegetative? If, when the patient's name is spoken, a PET or fMRI scan shows significant activity in the regions of the brain that process auditory language, does that mean the patient is in some way aware?

Neuroscientists working at the cutting edge of this technology warn against drawing such conclusions, for there are differing theories as to what patterns of neural activity constitute evidence of consciousness. One theory, for example, is that not all neural activity evoked by a stimulus is indicative of consciousness; activity in some brain regions may be associated with conscious perception but in other brain regions it may

\footnotetext{
${ }^{24}$ See Axel Cleeremans, Computational correlates of consciousness, in The Boundaries of Consciousness, Neurobiology and Neuropathology 81, 82 (Steven Laureys ed., 2005).

${ }^{25}$ See, e.g., Adrian M. Owen, et al., Detecting Awareness in the Vegetative State, 313 Sci. 1402 (Sept. 8, 2006).
} 
merely reflect non-conscious processing. ${ }^{26}$ Admonishments like these are common:

- "Functional neuroimaging cannot (and should not) replace bedside clinical evaluation as the criterion for assessment patients with disorders of consciousness. $" 27$

- " $[\mathrm{R}]$ esults from these studies should be interpreted cautiously for as long as we do not fully understand the neuronal basis of consciousness." 28

- "An appropriate neural response..., although suggestive, is not unequivocal evidence that a person is consciously aware." 29

- "This is not ready for prime time."30

The law, in any case, does not account for these advances in neuroscience.

\section{Legal Definitions of Unawareness: Behavioral vs. Functional}

Most state statutes governing surrogate end-of-life decision-making predate the 2002 formalization of the diagnosis of minimal consciousness and address only coma and the permanent vegetative state, providing legal definitions of unawareness within the context of the terms "permanent unconsciousness" or "persistent vegetative state." Some of these statutes define unawareness behaviorally, others functionally.

Here are some examples of statutory language that defines unawareness behaviorally:

- Florida: "absence of voluntary action or cognitive behavior of any kind" and "inability to communicate or interact purposefully with the environment." $" 31$

\footnotetext{
${ }^{26}$ See Stanislas Dehaene, et al., Conscious, preconscious, and subliminal processing: a testable taxonomy, 10 TRENDS in Cognitive Sciences 204 (May 2006).

${ }^{27}$ Joseph T. Giacino, et al., Functional Neuroimaging Applications for Assessment and Rehabilitation Planning in Patients With Disorders of Consciousness, 87 Arch. Phys. Med. Rehab. S69 (Dec. 2006).

${ }^{28}$ Steven Laureys, Death, unconsciousness and the brain, 6 Nature Reviews 905 (Nov. 2005).

${ }^{29}$ Adrian M. Owen, et al., supra note 25.

${ }^{30}$ Kelli Smith, Looking for hidden signs of consciousness, 446 Nature 355 (Mar. 22, 2007) (quoting Nicholas Schiff).

${ }^{31}$ Fla. Stat. $\S 765.101(12)(2007)$.
}

- Alabama: "cognitive thought, sensation, purposeful action, social interaction, and awareness of self and environment are absent." 32

- Delaware: "total and irreversible loss of consciousness and capacity for interaction with the environment." 33

- Connecticut: "the individual is at no time aware of himself or herself or the environment and shows no behavioral response to the environment."34

- Maryland: "a patient has suffered a loss of consciousness, exhibiting no behavioral evidence of self-awareness or awareness of surroundings in a learned manner other than reflex activity of muscles and nerves for low level conditioned response."35

Here are some examples of statutory language that defines unawareness functionally:

- Idaho: "no higher cortical function and no awareness of self or environment." 36

- Maine: "the patient totally lacks higher cortical and cognitive function, but maintains vegetative brain stem processes.",37

- Ohio: "unawareness of one's being and environment" and "total loss of cerebral cortical functioning." 38

- West Virginia: "the person has intact brain stem function but no higher cortical function and has neither self-awareness or awareness of the surroundings in a learned manner." 39

\footnotetext{
${ }^{32}$ Ala. Code § 22-8A-3(10) (2007).

${ }^{33}$ Del. Code Ann. tit. 16, § 2501(r)(1) (2007).

${ }^{34}$ Conn. Gen. Stat. § 19a-570(10) (2007).

${ }^{35}$ Md. Code Ann., Health-Gen § 5-601(o)(1) (West 2007). Other state statutes that define unawareness behaviorally include: Ga. Code Ann. § 31-32-2(13) (2007); 755 Ill. Comp. Stat. § 40/10 (2007); Neb. Rev. Stat. § 20-403(6) (2007); N.J. Stat. Ann. § 26:2H-55 (2007); 20 Pa. Cons. Stat. § 5422 (2007); S.D. Codified Laws § 34-12D-1(7) (2007); Va. Code Ann. § 54.1-2982 (2007).

${ }^{36}$ Idaho Code Ann. § 39-4502(10) (2007).

${ }^{37}$ Me. Rev. Stat. Ann. tit. 18-A § 5-801(s) (West 2007).

${ }^{38}$ Ohio Rev. Code Ann. $\S \S 1337.11(\mathrm{~V}), 2133.01(\mathrm{U})$ (West 2007).

${ }^{39}$ W. Va. Code $\S 16-30-3$ (s) (2007). Other state statutes that define unawareness functionally include: S.C. Code Ann. § 44 77-20(7) (2007); Utah Code Ann. § 75-2-1103(8).
} 
At least two states define unawareness both behaviorally and functionally-for example, the Kentucky definition is "an absence of cerebral cortical functions indicative of consciousness or behavioral interaction with the environment." 40 A few others, such as Oregon, define unconsciousness with neither a behavioral nor a functional bent, simply using language like "awareness of self and external environment." ${ }^{, 41}$ And many state statutory schemes do not define awareness at all-for example in California, ${ }^{42}$ Iowa, ${ }^{43}$ New Mexico ${ }^{44}$ and Hawaii. ${ }^{45}$

Case law, too, vacillates between behavioral and functional definitions of awareness. For example, in the seminal 1976 right-to-die case Matter of Quinlan, the New Jersey Supreme Court quoted an expert witness's functional definition of a vegetative patient as "“a subject who remains with the capacity to maintain the vegetative parts of neurological function who...no longer has any cognitive function." ${ }^{46}$ Yet in 1987, in Matter of Jobes, the same court used a behavioral definition as "no behavioral awareness of the surroundings in a learned manner.",47

In short, many existing statutory and judicial definitions of the vegetative state do not account for the diagnosis of minimal consciousness, the advent of functional brain-imaging technology that may theoretically provide evidence of consciousness, or both.

\footnotetext{
${ }^{40}$ Ky. Rev. Stat. Ann. § 311.621(12) (West 2007); see also Wis. Stat. Ann. § 154.01(5m) (2007) ("complete and irreversible loss of all of the functions of the cerebral cortex . . . and a complete lack of behavioral responses that indicate cognitive functioning").

${ }^{41}$ Or. Rev. Stat. § 127.505(18) (2007); see also Ark. Code Ann. $\S 20-17-201(6)$ (2007); N.H. Rev. Stat. Ann. § 137-J:2(XVII) (2007).

${ }^{42}$ Cal. Prob. Code $\S \S 4605-4643$ (West 2007).

43 Iowa Code $\S 144$ A. 2 (2007).

${ }^{44}$ N.M. Stat. § 24-7A-1 (2007).

${ }^{45}$ Haw. Rev. Stat. § 327E-2 (2007). Other state statutes that do not define awareness include: Ariz. Rev. Stat. § 36-3202 (2007); Minn. Stat. § 145C.01 (2007); N.Y. Public Health Law $\S 2965$ (McKinney 2007); N.D. Cent. Code § 23-06.5-2 (2007); Tenn. Code Ann. § 32-11-103 (2007); Wash. Rev. Code $\$ 70.122 .020$ (2007).

4670 N.J. 10, 24, 355 A.2d 647, 654.

${ }^{47} 108$ N.J. 394, 403, 529 A.2d 434, 438.
}

\section{Potential Impact on Surrogate End-of-Life Decision-Making}

Statutory Restrictions

The potential impact of functional brain imaging on surrogate end-of-life decision-making is perhaps greatest in states where legislation restricts surrogate refusal of artificial nutrition and hydration to conditions like terminal illness and permanent vegetative state. In those states, the impact may depend on whether state law defines awareness behaviorally or functionally.

For example, in Ohio, the withholding or withdrawing of artificial nutrition or hydration by a surrogate named in a patient's advance directive is statutorily restricted to situations where the patient is in a "terminal condition" or "permanently unconscious state." 48 Because Ohio law defines awareness functionally, ${ }^{49}$ the refusal of feeding tubes might well be treated as statutorily prohibited - regardless of what the patient might have said in an advance directive - if an fMRI or PET scan detects neural correlates of consciousness.

The situation is different in Florida, where the statutory authorization for surrogate refusal of artificial nutrition and hydration includes "persistent vegetative state" but does not mention other disorders of consciousness such as the minimally conscious state. Because Florida's statutory definition of awareness is behavioral, ${ }^{50}$ the detection of neural correlates of consciousness through fMRI or PET imaging should not preclude a diagnosis of permanent vegetative state within the meaning of Florida law. Thus in Florida, unlike Ohio, functional brain imaging should not affect the outcome of a future case like Schiavo. Even if fMRI or PET technology had revealed neural correlates of consciousness in Terri Schiavo, that in itself should not have cast doubt on her diagnosis, given Florida's behavioral definition of the vegetative state.

Florida's statutory authorization for surrogate refusal of feeding tubes also includes "end-stage

\footnotetext{
${ }^{48}$ Ohio Rev. Code Ann. $\S \S 1337.13(\mathrm{E}), 2133.08(\mathrm{~A})(1)(\mathrm{a})$, 2133.09(c)(2) (West 2007).

${ }^{49}$ See supra note 38 and accompanying text.

${ }^{50}$ See supra note 31 and accompanying text.
} 
condition" in addition to "terminal condition" and "persistent vegetative state." 51 The statute defines end-stage condition as "an irreversible condition that is caused by injury, disease, or illness which has resulted in progressively severe and permanent deterioration." 52 Similar provisions appear in some other state statutory schemes. ${ }^{53}$ It is possible that minimal consciousness might in some instances be viewed in those states as constituting an end-stage condition and thus being within an authorization for refusal of feeding tubes regardless of whether functional brain imaging is treated as precluding a diagnosis of permanent vegetative state.

\section{Advance Directives}

Functional brain imaging could also affect the scope and efficacy of advance directives in many statesagain, depending on whether state law defines awareness behaviorally or functionally. Most people who execute advance directives use prepared forms, and many of those forms - particularly the optional forms set forth in many state statutory schemes - are couched in language of vegetativeness or unconsciousness, which implicates definitions of awareness.

For example, West Virginia's statutory form advance directive applies, by its express wording, only when a physician certifies that the patient has "a terminal condition" or is "in a persistent vegetative state." ${ }^{54}$ Because West Virginia law defines awareness functionally, ${ }^{55}$ a West Virginia court might well conclude that an instruction in the language of the form advance directive - e.g., for refusal of feeding tubes if the patient is "in a persistent vegetative state" does not apply where fMRI or PET imaging detects neural correlates of consciousness. Thus, any West Virginian who wishes not to be kept alive in a state of minimal consciousness that is suggested solely by functional brain imaging would be well advised to say

\footnotetext{
${ }^{51}$ See supra note 9 and accompanying text.

${ }^{52}$ Fla. Stat. § 765.101(4) (2007).

${ }^{53}$ See, e.g, Md. Code Ann., Health-Gen $\S \S 5.601(i)$, 5.603; Okla. Stat. tit. 63, $\S \S 3101.3-.4$; Or. Rev. Stat. $\S 127.635(1)$.

${ }^{54}$ W. Va. Code $\S 16-30-4$ (g) (2007).

${ }^{55}$ See supra note 39 and accompanying text.
}

so in special instructions added to the statutory form, which West Virginia law permits. ${ }^{56}$

There is a further consideration in states like Maine - another state that defines awareness functionally ${ }^{57}$ where the statutory form advance directive addresses not just terminal illness and "unconscious" but also situations where "the likely risks and burdens of treatment would outweigh the expected benefits," 58 a formulation that appears in many form advance directives. ${ }^{59}$ Maine's functional definition of awareness might mean that a Maine court would treat the detection of neural correlates of consciousness as precluding a diagnosis of "unconscious" within the meaning of the statutory form, but it is still possible the surrogate could refuse artificial nutrition and hydration on the ground its risks and burdens would outweigh its expected benefits.

Some forms are structured so that there are separate statements of preference for different conditions. For example, Oregon's statutory form calls for separate instructions for "close to death," "permanently unconscious," "advanced progressive illness," and "extraordinary suffering." 60 Maryland's statutory form calls for separate instructions for "terminal condition," "persistent vegetative state," and "endstage condition." ${ }^{\prime \prime}$ In states like Oregon and Maryland that define awareness behaviorally, functional brain imaging that detects neural correlates of consciousness should not affect the determination whether a patient is "permanently unconscious" or in a "persistent vegetative state" for purposes of invoking an instruction for that condition. The result could be different, however, in states that defines awareness functionally. In those states, again, anyone who wishes not to be kept alive in a state of minimal consciousness that is suggested solely by functional brain imaging should say so in special instructions.

\footnotetext{
${ }^{56}$ See W. Va. Code $\S 16-30-4$ (g) (2007) ("The living will may, but need not, be in the following form and may include other specific directions not inconsistent with other provisions of this article.").

${ }^{57}$ See supra note 37 and accompanying text.

${ }^{58}$ Me. Rev. Stat. Ann. tit. 18-A § 5-804(6)(a) (West 2007).

${ }^{59}$ See, e.g., Cal. Prob. Code $\S 4701$ (West 2007); N.M. Stat. \$24-7A-4 (2007).

${ }^{60}$ Or. Rev. Stat. § 127.531 (2007).

${ }^{61}$ Md. Code Ann., Health-Gen $\S 5-603$ (West 2007).
} 
What should such special instructions say? How "special" should one get? The lawyers among us might be tempted to draft something like this:

I hereby authorize my surrogate to withhold or withdraw artificial nutrition and hydration if I am in a permanent vegetative state as diagnosed by a clinical evaluation of behavior, even if there is significant activation of my brain's calcarine cortex, extrastriate cortex or fusiform gyrus in response to visual stimuli, or similar activation of my network loci in response to auditory or noxious stimuli.

We should resist the temptation. The more specific an advance directive gets in prescribing conditions under which one would not want to be kept alive, the greater the danger that a condition not identified with such specificity will be treated as outside the scope of the directive. It ought to be sufficient - and is likely safer - to say something simple like this:

I hereby authorize my surrogate to withhold or withdraw artificial nutrition and hydration if I am in a condition that renders me permanently unable to interact behaviorally with people and my environment.

In any case, unless and until neuroscientists can reach consensus on whether and which patterns of neural activity detected by fMRI and PET scans constitute evidence of consciousness, people drafting and executing advance directives should consider speaking behaviorally rather than functionally. Language that invites functional definitions of awareness risks complications created by new imaging technologies and new discoveries about the brain that might lead to unforeseen notions of consciousness.

\section{Standards of Proof}

A unique question is presented in California because of that state's unusual approach to legal standards of proof in cases involving surrogate end-of-life decision-making. Nationally, the dominant standard of proof in such cases is the heightened civil standard of "clear and convincing evidence" rather than the usual civil standard of "preponderance of the evidence." 62

\footnotetext{
${ }^{62}$ See Alan Meisel \& Kathy L. Cerminara, supra note 4, at 3126.
}

In California, however, the applicable standard of proof can turn on whether the patient is persistently vegetative or minimally consciousness: For minimally conscious patients who made no advance directive and have a court-appointed conservator, the standard for determining the patient's end-of-life wishes (such as whether to have artificial nutrition and hydration) is clear and convincing evidence, but in all other cases the standard for determining end-of-life wishes is preponderance of the evidence. ${ }^{63}$

Consequently, the applicable standard of proof in California might turn on the results of functional brain imaging in some cases involving minimally conscious patients, depending on how the California courts choose to define awareness - behaviorally or functionally - which is currently an open question, because California is one of those states where there is no statutory definition of awareness. ${ }^{64}$

\section{Absence of Legal Definitions}

Absent a statutory or case-law definition of awareness, how is a state court to determine the impact of fMRI or PET technology on the determination whether a patient is in a permanent vegetative state? State courts confronting this issue will find an answer in the 1994 definition of the vegetative state by the Multi-Society Task Force on PVS and in the 2002 definition of the minimally conscious state by the Aspen Neurobehavioral Conference Workgroup. Those definitions are behavioral. Vegetative patients "show no evidence of sustained, reproducible, purposeful, or voluntary behavioral responses to visual, auditory, tactile, or noxious stimuli." ${ }^{65}$ Minimally conscious patients demonstrate "minimal but definite behavioral evidence of self or environmental awareness. $^{66}$

Thus, from a neuroscientific perspective, covert signs of awareness that are produced by functional brain imaging should have no impact on medical diagnoses of permanent vegetative state or minimally conscious state, which currently depend solely on

\footnotetext{
${ }^{63}$ Conservatorship of Wendland, 28 P.3d 151 (Cal. 2001).

${ }^{64}$ See supra note 42 and accompanying text.

${ }^{65}$ Multi-Society Task Force on PVS, supra note 10 (emphasis added).

${ }^{66}$ J.T. Giancino et al., supra note 15 (emphasis added).
} 
overt signs of awareness that are revealed behaviorally. The courts should heed the neuroscientists' admonitions that fMRI and PET scans cannot yet replace clinical evaluation of behavior as the standard for distinguishing between the permanent vegetative and minimally conscious states ${ }^{67}$ - that this technology "is not ready for prime time." 68

\section{Substituted Judgment Decision-making}

And what of the patient who has no advance directive but spoke to friends and family members about endof-life wishes in strictly lay terms? The Schiavo case sparked a national dialogue on end-of-life choices. Untold numbers of Americans must have made oral statements in March of 2005 like this: "I would never want to be kept alive on machines or tubes like a vegetable." For them, absent an advance directive, the law would apply the substituted judgment model for surrogate exercise of autonomy rights, looking to the person's known preferences and values as revealed by such statements. ${ }^{69}$

When people say in conversation that they would not want to be kept alive "like a vegetable," what do they mean? Would the average American conclude that one is not a "vegetable," despite the absence of any behavioral signs of awareness, if fMRI or PET imaging detects increased neural consumption of oxygen or glucose in response to auditory or visual stimuli?

Not likely. When people voice fears of being kept alive "like a vegetable," they are usually thinking in terms of behavioral awareness, not blobs of color on a brain scan. Not many among us would want to be kept alive if they were permanently incapable of interacting with the people and things around them, regardless of whether fMRI or PET technology reveals neural correlates of consciousness. Yet there are certainly some who would want neural correlates of consciousness to be taken into account in any

\footnotetext{
${ }^{67}$ See supra notes $27-29$ and accompanying text.

${ }^{68}$ See supra note 30.

${ }^{69}$ See supra note 5 and accompanying text.
}

decision whether to withdraw life support, and their concerns, if voiced, should be addressed.

If fMRI and PET technology is not ready for prime time in the neurological realm of diagnosing the permanent vegetative and minimally conscious states, it likewise is not ready for prime time in the minds of ordinary Americans who voice preferences not to be kept alive "like a vegetable." For substituted-judgment decision-making, such expressions of end-of-life wishes should be assessed primarily from a behavioral perspective and should not turn on the results of functional brain imaging absent knowledge that the person would prefer a functional assessment.

\section{Conclusion}

According to the neuroscientists, there is not a neurological test that would have shown whether Terri Schiavo was truly in a permanent vegetative state - at least not yet. Covert signs of awareness produced by fMRI and PET technology can provide tantalizing suggestions of consciousness, but functional brain imaging cannot yet replace behavioral evaluation as the touchstone for end-of-life decision-making.

Courts should know this; state legislatures should know this; and drafters of written advance directives for healthcare should know this. Courts that are called upon to adjudicate disputes about life-sustaining treatment should understand the behavioral-functional dichotomy in statutory and case-law definitions of awareness, seek appropriate guidance from any applicable state-law definitions, and turn to the neuroscientific definitions of the permanent vegetative and minimally conscious states where state law is silent. Legislatures in states that define awareness functionally instead of behaviorally should reconsider those definitions in light of the neuroscientists' admonitions about the limits of functional brain imaging. And drafters of written advance directives form-writers as well as individuals - should consider using language for surrogate end-of-life decision-making that speaks behaviorally rather than functionally. 